\title{
Reliability Prediction Methods for Electronic Devices and Systems- A Review
}

\author{
Y.S. Thakur ${ }^{\# 1}$ D. K. Sakravdia ${ }^{\# 2}$ \\ ${ }^{1}$ Department of Electronics and Communication Engineering, \\ ${ }^{2}$ Department of Electrical Engineering \\ ${ }^{\#}$ Ujjain Engineering College, Ujjain, M. P India.
}

\begin{abstract}
:-
Reliability analysis of the electronic devices, subsystems and complex systems is the most important requirement of today's competitive era. To mitigate the premature failures, to improve the performance and the longer life of these components and systems The knowledge of root causes of failures of these devices and systems enables to obtain high product reliability. To address these reliability issues a wide range of reliability prediction methods are available for electronic systems. In this article various reliability prediction methods are discussed with their concepts of application, advantages and disadvantages also. On the basis of this comparative study recommendations can be made to use the respective methods to achieve the high reliability goals.
\end{abstract}

Keywords:-reliability prediction models, pof, bus, tds, lifecycle.

\section{INTRODUCTION}

Reliability assessment and enhancement of electronic devices and systems is the major concern of today's competitive era. The reliability issues should be addressed from the very beginning of the design phase to obtain high product reliability and this can be achieved through reliability predictions. The type of reliability prediction approach to be adopted depends upon the product development stages and its related reliability metric.[1,2]. Reliability prediction methods used to address the process of applying mathematical models and component data for the purpose of estimating the field reliability of a system before failure data are available for the system. Some of the objectives of reliability predictions are as follows:

- Identifying potential design weakness

- Assessing the feasibility of a reliable design

- Comparing different design and life-cycle costs

- Help to attain a reliable manufacturing process
- Providing Models for system reliability/ availability analysis

- $\quad$ Provide inputs to safety analysis

- Establishing goals for reliability tests

- $\quad$ Aiding in business decisions like budget allocation and scheduling

Several different methods have been development to achieve these objectives but there is no unique approach which can achieve all these objectives.[3]. This article reviews three main categories of reliability predictions often used in government and industry. First we will present these three methods with their advantages and disadvantages. Next they are rated according to a list of criteria which is representative of an ideal method. Finally a comparative table regarding the management of the above mentioned objectives.

\section{THE RELIABILITY PREDICTION METHODS}

The most common reliability prediction methods and their latest updates are listed in table -1 . These methods have been grouped in three categories:

- Empirical ( standard Based ) prediction methods

- Physics of failure methods

- $\quad$ Life-testing methods

The Empirical method utilizes statistical analysis of failure data, while the PoF utilizes the root cause analysis of failure mechanisms, failure modes and stresses. This method depends upon an understanding of the physical properties of the materials, operation processes and technologies used in the design. The life testing methods are used to determine reliability by testing a relatively large number of samples at their specified operation stresses or higher stresses and using statistical models to analyze data 
International Journal of Applied Engineering Research ISSN 0973-4562 Volume 13, Number 17 (2018) pp. 13063-13069

(C) Research India Publications. https://dx.doi.org/10.37622/IJAER/13.17.2018.13063-13069

Table 1. Non-Exhaustive list of assessed reliability prediction methods and their latest updates

\begin{tabular}{|c|c|c|}
\hline Name of the method & Name of the reliability prediction source & $\begin{array}{l}\text { Year of } \\
\text { process }\end{array}$ \\
\hline \multirow{14}{*}{$\begin{array}{l}\text { Empirical } \\
\text { (standard based) } \\
\text { prediction method } \\
\text { (BUS+TDS) } \\
\text { Method }\end{array}$} & NTT procedure & 1985 \\
\hline & SAEreliability prediction method & 1987 \\
\hline & CNET RDF-93 & 1993 \\
\hline & Mil-Hdbk-217 & 1995 \\
\hline & British Telecom & 1995 \\
\hline & Telecordia SR-332 & 1997 \\
\hline & Siemens SN29500 & 1999 \\
\hline & Honeywell in service reliability assessment program(HIRAP)similarity analysis method & 1999 \\
\hline & DERA Transport reliability assessment and calculation system (TRACS) & 1999 \\
\hline & Reliability analysis center PRISM & 2000 \\
\hline & REMM reliability enhancement methodology and modelling & 2001 \\
\hline & FIDES & 2009 \\
\hline & NSWC mechanical commercial/ french & 2011 \\
\hline & Bellcore/Telcordia & 2011 \\
\hline \multirow{2}{*}{$\begin{array}{l}\text { Physics of } \\
\text { failure(BUS) }\end{array}$} & Airbus-Giat use of manufacturer testing results & 1999 \\
\hline & CADMP, calcePWA, calceFAST CALCE EPSC & 2001 \\
\hline Life testing method & Relia-soft webull++ & \\
\hline
\end{tabular}

In this article we clarify the different conditions to apply these methods.

\section{Empirical (standard Based) prediction methods:}

Empirical method can be divided into two categories

- BUS (Bottom-up statistical) methods and

- TDS (Top-down similarity) analysis methods.

BUS (Bottom-up statistical) methods: Empirical prediction methods are based on models developed from statistical curve fitting of historical failure data, may be collected from the field, in house or from manufacturers. These methods tend to present good estimate of reliability for similar or slightly modified parts. The assumption is made that system or equipment failure causes are inherently linked to components whose failures are independent of each other.

The BUS methods utilize the MIL-HDBK-217 predictive methods consists of two parts: one is known as the parts count method and the other is called the part stress method. The parts count method assumes typical operating conditions of part complexity, ambient temperature, various electrical stresses, operation mode and environment (called reference conditions). The failure rate for a part under the reference conditions is given as:

$$
\lambda_{\mathrm{b}, \mathrm{i}}=\sum_{i=1}^{n}\left(\lambda_{\mathrm{ref}}\right) \mathrm{i}
$$

Where:

- $\quad \lambda_{\text {ref }}$ is the failure rate under the reference conditions

- $\mathrm{i}$ is the number of parts

The part stresses method requires the specific part's complexity, application stresses, environmental factors etc.Mil-HDBK-217provides many environmental conditions (expressed as $\pi_{\mathrm{E}}$ ) ranging from "ground benign" to "cannon launch". The failure rate for parts under specific operating conditions can be given as:

$$
\lambda=\sum_{n=1}^{n}\left(\lambda_{\text {ref,i }} \times \pi_{\mathrm{s}} \times \pi_{\mathrm{T}} \times \pi_{\mathrm{E}} \times \pi_{\mathrm{Q}} \times \pi_{\mathrm{A}}\right)
$$

Where:

- $\pi_{\mathrm{s}}$ is the stress factor

- $\pi_{\mathrm{T}} \quad$ is the temperature factor

- $\pi_{\mathrm{E}} \quad$ is the environment factor

- $\pi_{\mathrm{Q}} \quad$ is the quality factor

- $\pi_{\mathrm{A}} \quad$ is the adjustment factor 
Bellcore/ Telcordia standard assumes a serial model for electronic products and addresses failure rates at the infant mortality stage and at the steady state stage with the methods I,II AND III. Method I is similar to the MIL-HDBK-217F parts count and part stress methods. The standard provides generic failure rates and three part stress factors: device quality factor $\left(\pi_{\mathrm{Q}}\right)$, electrical stress factor $\left(\pi_{\mathrm{S}}\right)$ and temperature stress factor $\left(\pi_{\mathrm{T}}\right)$.Method II is based on combining data from laboratory test performed in accordance with specific SR-332 and method I predictions. In method III, the predicted failure rate is a weighted average of the generic steady-state failure rate and field failure rate and data collected in accordance with specific SR-332 criteria.

TDS (Top-down similarity) analysis methods: In top-down similarity analysis method comparative analysis is made between previous systems or sub-system with known reliability and newly designed systems. Instead of only component failure rates, all failure causes are considered and therefore the failure cause analysis is very important. Following are the steps involved in this method:

- Failure data collection from the field

- Determination of the failure rates for equipment/board failure causes not related to piece parts and interconnects.

- Field data assessment (equipment/board failure causes, calculation of the associated reliability.)

- Circuit card assembly (CCA) level failure rates determination, based on the number of unique CCAs per equipment.

- Failure rates determination at the piece part and interconnects levels based on the number of piece parts and interconnects per CCA.

- In service Failure rate database creation with all previous piece of information according to the following physical model categories: semiconductor (low/high complexity) design process, manufacturing process, interconnections, passive (low/high), other failure causes.

- Comparison between existing and proposed designs with the following steps:

Review products whose field data is available

- Identification of characteristics differences (e.g. manufacturing, design and so on)

- Quantify the impact of the characteristics differences on each physical model category

- Field data incorporation with percent of each physical model category, overall end item or assembly failure rates.

- Calculate the new item(board, CCA or equipment) failure rate according to:

$$
\lambda=\lambda_{p} \sum_{a=1}^{n}\left(\mathrm{D}_{\mathrm{a}} \times \mathrm{F}_{\mathrm{a}} \mathrm{d}\right)
$$

Where $\lambda_{p}$ is the field failure rate for the predecessor item, $\mathrm{D}_{\mathrm{a}}$ is the distribution percentage for physical model category $\mathrm{a}, \mathrm{F}_{\mathrm{a}}$ is the difference factor between the new and previous items for category a, and $\mathrm{n}$ is the total number of physical model categories.

Physics of failure methods: The physics of failure method based on the understanding of failure mechanism and applying this model to data. The physics of failure method requires the knowledge of thermal, electrical mechanical and chemical life cycle environment and processes leading to failures in the field. Several popularly used models are listed below:

- Arrhenius's law of temperature

- Eyring model

- Two temperature/voltage model

- Three stress model( temperature-voltage-humidity)

- Corrosion model

- Hot carrier injection model

- Black model for electro migration

- Coffin-Manson model for Fatigue

Arrhenius's law of temperature: This the most successful earliest model predicts how the time to failure of a system varies with temperature and given by:

$A F=\exp \left[\frac{E_{a}}{k}\left(\frac{1}{T_{1}}-\frac{1}{T_{2}}\right)\right]$

Where, $\mathrm{AF}$ is the acceleration factor. $E_{a}$ is the activation energy of the failure mechanism, $\mathrm{k}$ is the Boltzman constant, $T_{1}$ and $T_{2}$ are the temperature of use and stress respectively.

Eyring models: This model demonstrates the dependency of reactions on stress factors other than temperature e.g. mechanical stress, humidity or voltage and is given as:

$\mathrm{A}(\mathrm{T}, \mathrm{S})=\mathrm{A} T^{\alpha} \exp \left\lfloor\frac{E_{a}}{K T}+\left(B+\frac{C}{T}\right) S\right\rfloor$

Where

- A (T, S) is the life characteristic related to temperature and other stress

- $\quad \mathrm{A}, \mathrm{B}, \mathrm{C}$ and $\alpha$ are the constants

- $\mathrm{S}$ is a stress factor other than temperature

- $\mathrm{T}$ is absolute temperature

Two temperature/voltage model: This can be given by

$\mathrm{L}(\mathrm{T}, \mathrm{V})=\mathrm{A} e^{\frac{E_{a}}{k T V^{-\beta}}}$

Three stress model( temperature-voltage-humidity) : This model is given as:

$\mathrm{L}(\mathrm{T}, \mathrm{V}, \mathrm{H})=\mathrm{A} e^{\frac{\Delta H}{k T V^{-\beta}}} R H^{-\tau}$ 
Corrosion model: Electronic devices with aluminium or aluminium alloy with small percentages of copper and silicon metallization are subject to corrosion failures and can be given as:

$\mathrm{L}(\mathrm{RH}, \mathrm{V}, \mathrm{T})=B_{0} \exp [(-a) R H] f(V) \exp \left(\frac{E_{a}}{k T}\right)$

Where

$\boldsymbol{B}_{\mathbf{0}}$ is an arbitrary scale factor $\boldsymbol{\alpha}$ is equal to 0.1 to 0.15 per $\% \mathrm{RH} \mathrm{f}(\mathrm{v})$ is an unknown function of applied voltage with empirical value of 0.12 to 0.15 .

Hot carrier injection model: In MOSFETS the carrier gains sufficient energy to be injected into the gate oxide, create bulk oxide defects and degrade MOSFETS'S characteristics e.g. threshold voltage, transconductance etc.

For n-channel devices the method is given by:

$\mathrm{L}(\mathrm{I}, \mathrm{T})=\mathrm{B}\left(\mathrm{I}_{\mathrm{sub}}\right)^{-\mathrm{N}} \exp \left(\frac{E_{a}}{k T}\right)$

Where

- $\mathrm{B}_{0}$ is an arbitrary scale factor

- Isub is the peak substrate current during stressing

- $\quad \mathrm{N}$ is equal to a value from 2 to 4 typically 3

- $\mathrm{E}_{\mathrm{a}}$ is equal to $-0.1 \mathrm{eV}$ to $-0.2 \mathrm{Ev}$

Black model for electro migration: Electro migration is a failure mechanism that results from the transfer of momentum from the electrons, which move in the applied electric conductor" is the most common failure. With decreased structure of IC's the increased current density makes this failure mechanism very important in IC reliability. The black model considers external heating and increased current density and is expressed as:

$\mathrm{MTTF}=\mathrm{A}_{\mathrm{O}}\left(\mathrm{J}-\mathrm{J}_{\text {thresold }}\right)^{-\mathrm{N}} \exp \left(\frac{E_{a}}{k T}\right)$

Where:

- Ao is a constant based on the cross- sectional area of the interconnect

- $\mathbf{J}$ is the current density

- J Jhresold is the threshold current density

- $\quad \boldsymbol{E}_{\boldsymbol{a}}$ is the activation energy

- $\quad \boldsymbol{k}$ is the boltazman constant

- $\boldsymbol{T}$ is the temperature

- $\quad \boldsymbol{N}$ is a scaling factor

The current density $(\mathrm{J})$ and temperature $(\mathrm{T})$ are the factors in the design process which affects the electro migration. Various experiments with various stress conditions reported in the literature, where the values reported within 2 and 3.3 for $\mathrm{N}, 0.5$ to $1.1 \mathrm{eV}$ for $\boldsymbol{E}_{\boldsymbol{a}}$.
Coffin-Manson model for Fatigue: Fatigue failures may occur in electronic devices due to temperature cycling and thermal shocks. The crack growth in solder due to temperature cycling due to device is switched on and off repeatedly is successfully modelled by Coffin-Manson model and is given as:

$\mathrm{N}_{\mathrm{f}}=\mathrm{Af}^{-\alpha} \Delta \mathrm{T}^{-\beta}\left(\mathrm{GT}_{\max }\right)$

Where:

- $\mathbf{N}_{\mathbf{f}}$ is the number of cycles to failure

- A is a constant

- $\mathbf{f}$ is the cycling frequency

- $\Delta \mathbf{T}$ is the temperature range during a cycle

- $\boldsymbol{\alpha}$ is the cycling frequency exponent

- $\boldsymbol{\beta}$ is the temperature exponent

- $\left(G T_{\max }\right)$ is given by following equation:

$G T_{\max }=\left(\frac{E_{a}}{K} \times \frac{1}{T_{\max }}\right)$

Which is an Arrhenius term evaluated at the maximum temperature in each cycle?

- Coffin- Manson based law for thermal cycling fatigue is given as:

$A F=\left(\frac{\Delta T_{2}}{\Delta T_{1}}\right)^{2}\left(\frac{F_{1}}{F_{2}}\right)^{0.33}-$

Where, AF is the acceleration factor, $\Delta T_{1}$ and $\Delta T_{2}$ are the amplitude of thermal variations of use and stress respectively, $F_{1}$ and $F_{2}$ are the frequency of the use and stress cycles respectively.

\section{Life-testing methods:}

The third type of reliability prediction method is life testing method. In life testing method a test is conducted on a sufficiently large sample of units operating under normal usage conditions. Times to failure are recorded and then analyzed with an appropriate statistical distribution in order to estimate reliability metrics. This type of analysis is often referred to as life data analysis or weibull analysis.

The life testing method is preferable over both Empirical and physics of failure methods when system level realistic predictions are necessary rather than component level. The empirical and physics of failure methods calculate the system failure rate based on component failure rates such as using the sum of the component failure rates if the system is considered to be a serial configuration. This assumes that there are no interaction failures between the components but, in reality due to the design or manufacturing, components are not independent. Therefore, in order to consider the complexity of the entire system, life tests can be conducted at the system level, treating the system as a "black box" and the system reliability can be predicted based on the obtained failure data. 


\section{FEATURES OF THE METHODS}

The main features of these methods are the sources of data, the inputs, the outputs and model's sensitivity. The sources of data and original-environment of all the methods are listed in table-II. It is better that the sources of data and the environment they come from should be more generic. However each of these methods considers different environments.BUS methods utilizes load fitted and environmental factors based only on the failure modes not on the failure causes for operating modes with or without storage.TDS methods depends on the regular updates of their failure in-service databases which depends upon the companies policies. Eventually, at each level (e.g. item, equipment, board, and component) failure rates to be stored for each cause of failures, all failures needs to be track down, and all removals needs to be analyzed. The BUS methods consider the component failures only and overlook the system level failures. The BUS methods may have following issues:

- To set up representative fittings a huge amount of experimental data is required.

- Due to data aging and component reliability improvement over the time these fittings become pessimistic. PRISM and HRD-5are designed to consider this reliability improvement but HRD-5 is insensitive to the component reliability.

- An aggregate figure of failures (extrinsic and intrinsic) is used without physical or mathematical justification.

Pof(physics of failure) methods use load profiles and methods like CALCE software requires a detailed information, which may be proprietary by manufacturers. For the choice of suitable models adaptable to actual failure mechanism a prior knowledge of failure mechanism of failed components is also needed. The Pof methods like Airbus-Giat consider only intrinsic failures and manufacturing process variations, While CALCE method overlooks the intrinsic failures.

However Pof methods are limited to component and board level computation therefore acceleration models should be chosen carefully. The Life Testing methods can provide more information about the electronic product than the empirical and Pof prediction methods. The life -testing methods may be preferred over both the empirical and Pof method when it is necessary to obtain more realistic and accurate predictions at system level rather than component level.

Table 2. Sources of data and environment of the reliability prediction methods

\begin{tabular}{|c|c|c|}
\hline $\begin{array}{l}\text { Name of the } \\
\text { method }\end{array}$ & Name of the reliability prediction source & $\begin{array}{l}\text { Sources of data } \\
\text { environment }\end{array}$ \\
\hline \multirow{9}{*}{$\begin{array}{l}\text { Empirical } \\
\text { (standard based) } \\
\text { prediction } \\
\text { method } \\
\text { (BUS+TDS) } \\
\text { Method }\end{array}$} & $\begin{array}{l}\text { NTT procedure } \\
\text { SAEreliability prediction method }\end{array}$ & $\begin{array}{l}\text { Telecom } \\
\text { Automotive }\end{array}$ \\
\hline & $\begin{array}{l}\text { CNET RDF-93 } \\
\text { Mil-Hdbk-217 }\end{array}$ & $\begin{array}{l}\text { Ground Military } \\
\text { Military }\end{array}$ \\
\hline & British Telecom & Telecom \\
\hline & Telecordia SR-332 & Telecom \\
\hline & $\begin{array}{l}\text { Siemens SN29500 } \\
\text { Honeywell in service reliability assessment program(HIRAP)similarity analysis } \\
\text { method }\end{array}$ & $\begin{array}{l}\text { Siemens products } \\
\text { Commercial aviation }\end{array}$ \\
\hline & DERA Transport reliability assessment and calculation system (TRACS) & Military vehicles \\
\hline & Reliability analysis center PRISM & Commercial military \\
\hline & $\begin{array}{l}\text { REMM reliability enhancement methodology and modelling } \\
\text { FIDES }\end{array}$ & $\begin{array}{l}\text { Automotive military } \\
\text { Commercial military }\end{array}$ \\
\hline & $\begin{array}{l}\text { NSWC mechanical commercial/ french } \\
\text { Bellcore/Telcordia }\end{array}$ & $\begin{array}{l}\text { Commercial } \\
\text { Telecom }\end{array}$ \\
\hline \multirow{2}{*}{$\begin{array}{l}\text { Physics of } \\
\text { failure(BUS) }\end{array}$} & Airbus-Giat use of manufacturer testing results & Not specific \\
\hline & CADMP, calcePWA, calceFAST CALCE EPSC & Not specific \\
\hline
\end{tabular}




\section{COMPARISON AND ASSESSMENT OF THE METHODS:}

These methods are compared based on some criteria and trade-offs needed between the amount of detailed information and the models usability in table-3. It is also very clear from the table that no single method addresses all criteria comprehensively. The important criteria are accuracy, resources, customization, and time to obtain reliability estimate, ability for evolution. This table summarizes these methods with these criteria subjectively rating the appropriateness of the criteria and method.

Table-3. Comparison criteria of the reliability prediction methods

\begin{tabular}{|l|c|c|c|c|}
\hline $\begin{array}{l}\text { Comparison } \\
\text { criteria }\end{array}$ & BUS & TDS & POF & $\begin{array}{c}\text { LIFE- } \\
\text { TESTING }\end{array}$ \\
\hline Accuracy & Relative & Absolute & Absolute & Absolute \\
\hline $\begin{array}{l}\text { Time to obtain } \\
\text { reliability } \\
\text { estimate }\end{array}$ & Short & Short & Long & Long \\
\hline $\begin{array}{l}\text { Ease of } \\
\text { customization }\end{array}$ & No & Yes & Yes & Yes \\
\hline $\begin{array}{l}\text { Ability for } \\
\text { evolution }\end{array}$ & Difficult & Yes & Yes & Yes \\
\hline Traceability & Difficult & Easy & Easy & Easy \\
\hline
\end{tabular}

From the table above shown it is clear that the reliability predictions may be absolute or relative from the accuracy point of view also some of methods are taking shorter time while some are taking relatively long time to estimate the reliability. Similarly some are easily traceable; customization is not possible for BUS but possible for all other methods. So it is recommended that the reliability prediction methods should be selected according to the requirements and fulfilling all other dimensions necessary.

\section{OBJECTIVE MANAGEMENT}

Another way to compare these methods is to rate them how much they are capable to achieve and satisfy the objectives stated in the introduction. A subjective evaluation is made based on their ability to contribute towards overall reliability, availability, maintainability, safety assessment process. The empirical data based methods BUS and TDS are appropriate for evaluating an average reliability figure for an average production, BUS may be appropriate for selection and management of components, warranty, maintenance planning etc. TDS methods offer a very good trade-off and satisfy most of the objectives but cannot be standardized because most of the data are proprietary. The Pof methods are fit for manufacturing improvement, board qualification and design trade-offs. The Life testing methods are fit for more accurate and realistic predictions at the system level rather than component level.

\section{CONCLUSION}

The all three reliability prediction methods (e.g. empirical, Pof and Life testing) have their own distinctive advantages and disadvantages. The empirical methods (BUS and TDS) can be used in the design stage to quickly obtain a rough estimation of product reliability. The Pof and Life testing methods can be used at both the stages i.e. at design and production stages. In Pof methods the model parameters can be obtained from test data or design specs while in Life -testing method the failure data are obtained from particular products. The life -testing methods are more accurate and realistic at system level rather than component level, therefore more accurate than Pof and empirical methods. It can be observed from the above discussion that the best reliability predictions can be achieved using a combination of different suitable methods at manufacturing, design or development phase.

\section{REFERENCES}

[1] Denson W. Rebuttal to: A critique of the ReliabilityAnalysis-Centre failure-rate-model for plastic encapsulated microcircuits. IEEE Trans Reliab 1998;47(4):419-24.

[2] MIL-HDBK-217F, Reliability Prediction of Electronic Equipment, 1991. Notice 1 (1992) and Notice 2 (1995).

[3] SR-332, Issue 1, Reliability Prediction Procedure for Electronic Equipment, Telcordia, May 2001.

[4] SR-332, Issue 2, Reliability Prediction Procedure for Electronic Equipment, Telcordia, September 2006

[5] B. Foucher, J. Boullie, B. Meslet and D. Das, "A Review of Reliability Prediction Methods for Electronic Devices," Microelectron. Wearout., vol. 42, no. 8, August 2002, pp. 1155-1162.

[6] M. Pecht, D. Das and A. Ramarkrishnan, "The IEEE Standards on Reliability Program and Reliability Prediction Methods for Electronic Equipment," Microelectron. Wearout., vol. 42, 2002, pp. 1259-1266.

[7] M. Talmor and S. Arueti, "Reliability Prediction: The Turnover Point," 1997 Proc. Ann. Reliability and Maintainability Symp., 1997, pp. 254-262.

[8] W. Denson, "The History of Reliability Prediction," IEEE Trans. On Reliability, vol. 47, no. 3SP, September 1998.

[9] SAE G-11 Committee, Aerospace information report on reliability prediction methodologies for electronic equip- ment AIR5286, Electronic reliability prediction sub-com- mittee, 31/01/98.

[10] Bowles J. A survey of reliability prediction procedures for microelectronic devices. IEEE Trans Reliab 1992;41(1): 2-12.

[11] Leonard C. On US Mil-Hdbk-217 and reliability prediction. IEEE Trans Reliability 1988;37:450-1.

[12] Leonard C. Failure prediction methodology 
calculations can mislead: use them wisely, not blindly. Proceedings of the National Aerospace and Electronics Conference NAECON 1989;4:1248-53.

[13] Wong KL. What is wrong with the existing reliability prediction methods? Qual Reliab Eng Int 1990;6(4):251-7.

[14] Wong KL. A change in direction for reliability engineering is long overdue. IEEE Trans Reliab 1993;42:261.

[15] Centre National d'Etude des T eeleecommunications.Hand- book of Reliability Data for Electronic Components RDF- 93 English Issue, 1993.

[16] UTEC 80810. Modeeleuniverselpourlecalculdelafiabilit ee preevisionnelledescomposants,carteset eequipements eelectroniques - RDF2000, (projet du 11/01/00).

[17] British Telecom, Handbook of Reliability Data, HDR$5,1995$.

[18] Siemens AG, Siemens Company Standard SN29500, Ver- sion 6.0, Failure Rates of Electronic Components, Sie- mens Technical Liaison and Standardization, 9 November 1999.

[19] Nippon Telegraph and Telephone Corporation, Standard Reliability Table for Semiconductor Devices, 1985.

[20] Denson W. A tutorial: PRISM. Reliab Analysis Center 1999;3rd quarter:1-6.

[21] Gullo L. In-service reliability assessment and top-down ap- proach provides alternative reliability prediction method. Ann Reliab Maintain Symp Proc 1999:365-77.

[22] Johnson B, Gullo L. Improvements in reliability assessment and prediction methodology.

[23] Internet website www.remm.org/REMM. Last modified 16 February 2001.

[24] Internet website www.agena.co.uk/tracs. Last modified 11 August 1999.

[25] Charpenel $\mathrm{P}$ et al. An other way to assess electronics part reliability. Microelectronics Reliability, Proceedings ES- REF 1997;37(10/11):1449-1452.

[26] Charpenel P, Cavernes P, Casanovas V. A new prediction- methodology on avionics embedded electronics: why? how? Ann Reliab Maintain Symp Proc 1999:378-82.

[27] Osterman M, Stadterman T. Failure assessment software for circuit card assemblies. Ann Reliab Maintain Symp Proc 1999:269-76.

[28] McCluskey P. Fatigue and intermetallic formation in lead free solder die attach. Proceedings of IPACK'01, The Pacific Rim/ASME International Electronic Packaging Technical Conference and Exhibition, paper \#44592, 9-13 July 2001. p. 1-7.
[29] McCluskey P. A web-based graduate course on the mechanical design of high temperature and high power electronics. Proceedings of the electronic component and technology conference, 30 May 2001. p. 397-400.

[30] Pecht M, Ramappan V. Are components still a major problem? A review of electronic systems and device field failure returns. IEEE Trans Comp Hybr Manufact Tech- nol 1992;15(6):1160-4.

[31] Denson W. The history of reliability prediction. IEEE Trans Reliab 1998;47(3-SP):321-8.

[32] Jones J, Hayes J. A comparison of electronic reliability prediction models. IEEE Trans Reliab 1999;48(2):12734. 